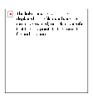

\title{
Advances in Tourism Economics: the Sixth IATE (International Association for Tourism Economics) Conference
}

\begin{tabular}{|r|l|}
\hline Journal: & Tourism Economics \\
\hline Manuscript ID & Draft \\
\hline Manuscript Type: & Review Article \\
\hline Keywords: & IATE Conference, Tourism Economics, Review \\
\hline Abstract: & No abstract \\
\hline \multicolumn{2}{|l}{} \\
\hline
\end{tabular}

\section{SCHOLARONE ${ }^{\text {Wh }}$ \\ Manuscripts}




\section{Advances in Tourism Economics: the Sixth IATE (International Association for Tourism Economics) Conference.}

This Special Issue contains a selection of the papers presented at the $6^{\text {th }}$ Conference of the IATE International Association for Tourism Economics, hosted by the University of Bologna, Rimini Campus, between June the 20th and June the 23rd, 2017. The Conference, which built upon the previous editions held at University of Balearic Islands (2007), Chiang Mai University (2009), Bournemouth University (2011), University of Ljubljana (2013) and Hong Kong Polytechnic University (2015), was co-organized by the Department of Economics and by CAST - the Centre for Advanced Studies in Tourism of the University of Bologna, an inter-departmental research centre aimed at fostering advanced scientific research and professional training in the tourism field. Overall, the Conference received 199 submissions. Each submission was reviewed by 2 anonymous referees and the scientific committee decided to accept 171 papers. Net of withdrawn papers and of authors who could not attend the conference, 142 papers were presented.

After the Conference, 19 papers were submitted to this special issue and the six selected papers are those that survived Tourism Economics journal's rigorous peer review process and whose authors were persistent and accommodated the requirements for revisions to the original submissions. ${ }^{1}$ The selection of the articles was largely influenced by the novelty of their approach and by the contribution to the economics of tourism's literature. They are representative of the important effort that the IATE, the journal Tourism Economics, and the whole community of economists of tourism are undertaking to increase the quality of research in this field of study. Not only the Conference witnessed an increase in the number of submitted papers with respect to previous editions, but also a visible improvement in the scientific approach, in the applied methodologies, in the relevance for the whole economic discipline, and in the variety of topics covered. Several sessions on topics such as tourism demand in destinations, climate change, economic growth, pricing strategies, tourism modelling and forecast, big data in tourism, sharing economy, experiential tourism, the economic impact of tourism, innovation, competitiveness, economic modelling, sustainability, tourism development and poverty tackling, tourism policy and taxation, labour market and the human capital were organised within the Conference.

Of such enormous variety of themes, six crucial concerns of tourism economics are tackled by the selected papers. As the attractiveness of a destination highly depends on income elasticity of tourism demand, Falk \& Xiang (2018) show in their paper how long-run elasticity varies over time and, beyond events that cause structural breaks, depends on tourism life cycle phases. By using a smooth time-varying cointegration regression approach, they provide evidence for the stability of the long-run income elasticity of overnight stays for domestic and incoming tourists in Switzerland. The novelty of the paper's contribution includes the approach adopted, able to tackle structural changes and non-stationary data, and the long time series used (from 1934 to 2015). The analysis goes beyond short or medium-terms effects of income elasticity in specific phases of the life cycle, topics already covered in the literature, and distinguishes different tourism segments with different characteristics over the long run. In particular, the authors separate the analysis for leisure tourists and business travelers. The empirical evidence highlights a time-varying long-run relationship between tourism demand and GDP per capita.

Another important topic for the tourism destination is the study of its pattern of evolution over time. In his paper Simone Marsiglio (2018) provides a theoretical explanation rooted in the endogenous growth theory regarding the relationship between tourism specialization and structural change, with

1 We would like to thank the guidance and support of Tourism Economics' editors, Albert Assaf and Raffaele Scuderi, and a long list of reviewers for their thoughtful suggestions and constructive criticism. 
implications for both economic growth and tourism flows. A stylized two-sector economic growth model driven by structural change is presented, where tourism specialization plays two important roles: it gives rise to a sectoral shift and generates a production externality. By embracing a balanced growth path equilibrium approach, Marsiglio's paper investigates the conditions under which a sectoral shift could be beneficial for economic growth, and whether such a positive effect could be long-lasting. While his contribution is purely theoretical - and tourism economics badly needs theoretical applications like this one - the findings bring to light some interesting new results on the ongoing efforts to better understand the economic channels linking tourism and economic growth. As such, the suggested model explains how tourism specialization could drive to a temporary period of fast economic growth in destinations and why it could also give rise to different phases of growth that are compatible with the predictions of tourism area life cycle hypothesis.

The next two papers deal with factors affecting productivity and competitiveness of the tourism sector. The first is associated with investment in innovation; the second one looks at job satisfaction. In the literature, empirical analyses on the drivers of innovation in the service sector are not common, given the peculiarity of the output. Applications to the tourism sector are even rarer. In their contribution to fill this gap, Divisekera \& Van Nguyen (2018) analyze the determinants of innovation in the tourism sector by distinguishing the types of innovation (product, process and organizational). The authors consider the inputs suggested by the literature and divide them into innovation inputs (collaboration, human capital, information technology and funding) and market and firm characteristics. Through a set of logistic regressions and an approach from general to specific, the authors highlight what types of inputs positively contribute to the different forms of innovation in a sample of Australian firms. An interesting result which emerges from the analysis is that the collaboration among firms, not very common in the tourism sector, is a key factor for all types of innovation, although with different intensity. The other factors affect only one or two types of innovation. Human capital, in particular, has a positive impact on product innovation and organizational processes. Information technology affects process innovation and firm organization. Some features of the market and of the firm also affect the propensity to innovate.

The other contribution recognizes how the satisfaction of workers affects their commitment and performance and, consequently, firm productivity and competitiveness. Lillo-Bañuls, Casado-Diaz and Simón (2018) firstly argue that workers in the tourism sector are, in general, less satisfied than workers in other comparable sectors. In fact, tourism is a labor-intensive sector with a large share of low-skilled workers, whose low satisfaction is, in general, linked to the characteristics of their job position (longer working days, lower pay, etc.). Secondly, by analyzing a large sample of workers in Spain, the authors identify the determinants affecting job satisfaction in the tourism sector in comparison with analogous job positions in other sectors. The empirical evidence highlights that there are several determinants affecting only tourism workers' or only non-tourism workers' wellbeing. The inclusion of workers in tourism activities other than the accommodation sector is a novel contribution of the paper to the literature.

The last two papers address issues related to international tourism and trade. An important feature of globalization is the international fragmentation of production. This phenomenon has been studied for goods and for certain service activities but has remained largely unnoticed in tourism studies. The paper by Fuster, Lillo-Bañuls and Martinez-Mora (2018) provides insights regarding the trends in offshoring in the service sector in Spain over the 2000-2007 period, with a particular focus on tourism-related activities. The authors explain how offshoring can be measured and monitored at the macro level through the use of various indices based on data coming from Input-Output tables. A wide range of criteria have been presented to assess different forms of offshoring. A distinction is made between inter-sectoral and intra-sectoral offshoring as well as offshoring associated to international fragmentation of production and offshoring due to shifts from domestic to foreign suppliers. Empirical results suggest that tourism-related activities are strongly impacted by this 
paradigm of global competition. However, there seems to be differences in the patterns and types of offshoring across tourism activities (travel agencies, maritime transport, air transport, travel agencies, accommodation services, etc.).

Finally, although the relevance of international trade theory for tourism economics has been recognized for some time, to the best of our knowledge, the paper by Tubadji and Nijkamp (2018) constitutes the first empirical investigation of the Balassa-Samuelson effect in the context of international tourism. In their seminal paper Balassa and Samuelson argued that production technologies differ among countries and that high-income countries have a comparative advantage in those sectors requiring high labour productivity. They also observed that the price of non-traded goods or services (including tourism activities) is higher in countries with high labour productivity. In this context, both authors separately acknowledged the importance that international tourism could play in balancing the purchasing power parities (PPP) between countries, by fostering international mobility of consumers. The novel contribution of Tubadji and Nijkamp is to empirically assess the contribution of tourism as a mechanism for the Balassa-Samuelson effect and to address the role of cultural proximity, or 'home bias', in the choice of tourism destinations. The authors use data for the 34 OECD countries as well as for the $28 \mathrm{EU}$ economies to support the Balassa-Samuelson effect. Furthermore, the findings suggest that the variable "linguistic proximity" is the most powerful proxy for the cultural bias effect among the six Hofstede cultural dimensions indices used in the study.

As stated at the beginning of this introduction, this special issue is only the tip of the iceberg representing ongoing research in the economics of tourism. Much more is still under the water, and the next opportunity to emerge will be the $7^{\text {th }}$ IATE Conference, which will be hosted by the University of La Plata, Argentina, in 2019.

\section{References}

Divisekera, S., Van Nguyen, 2018. Drivers of innovation in tourism: an econometric study, Tourism Economics, this issue.

Falk, M., Lin, X., 2018. Income elasticity of overnight stays over seven decades, Tourism Economics, this issue.

Fuster, B., Lillo-Bañuls, A., Martínez Mora, C., 2018. Offshoring of services as a competitive strategy in the tourism industry, Tourism Economics, this issue.

Lillo-Bañuls, A., Casado-Díaz, J., Simón, H., 2018. Examining the determinants of job satisfaction among tourism workers, Tourism Economics, this issue.

Marsiglio, S., 2018. On the implications of tourism specialization and structural change in tourism destinations, Tourism Economics, this issue.

Tubadji, A., Nijkamp, P., 2018. Revisiting the Balassa-Samuelson effect: international tourism and cultural proximity, Tourism Economics, this issue. 